\title{
SIMULATION SOFTWARE AS A CALCULATION TOOL FOR TRAFFIC CAPACITY ASSESSMENT
}

Every town faces many problems one of which is ensuring good traffic situation in its territory. Road network in towns is limited by density of existing buildings and every traffic increase can lead to road network overcrowding. Therefore towns have to plan the future traffic in the way the roads are prevented from occurring traffic problems. In order to prevent traffic problems within the city every larger investment plan which may have impact on traffic has to come under the traffic capacity assessment before is approved by city. This paper is focused on various tools that may be used in traffic capacity assessment of every greater investment plan. You can find comparison of Aimsun simulation outputs, OmniTrans simulation outputs, and outputs of analytical calculation according to technical regulations valid in Slovakia in this paper.

Keywords: Delay times, traffic capacity assessment, aimsun, technical regulations, omnitrans.

\section{Introduction}

Good traffic situation is one of the objectives of every town. Road network in towns is limited by density of existing buildings and every traffic increase can lead to road network overcrowding, which may result in undesirable external costs such as traffic congestions, increased fuel consumption, and higher production of greenhouse gases and noise. This all ultimately reduces the attractiveness of the area. In order to achieve traffic sustainability all greater investment projects of developers that may have impact on the traffic have to come under traffic-capacity assessment, which is standard part of the preparatory or project documentation at present. Good traffic situation is important for both sides -for the town and its inhabitants and for the developers. But methods relating to traffic-capacity assessment used in approval process of investment plans may be processed non-uniformly, they may differ in the range of processing and may reflect a subjective approach of their processors [1, 2, 3 and 4]. Therefore, there is effort of the competent authorities to establish a uniform methodology for assessing the project documentation. Bratislava gave to create the methodology with uniform traffic engineering methods in order to avoid differences in approaches to the traffic-capacity assessments of great investment projects in its territory. Similar methodology is also applied in Presov. This methodology was based on the methodology of Bratislava, but it was modified in order to suit the conditions of the town Presov.
According to these methodologies the traffic-capacity calculations are carried out with the help of analytical methods and there are 3 basic junction types [5]:

- Uncontrolled junctions, where analytical calculations are set in Slovak standard STN 736102 [6] and in Technical regulations TP 10/2010 [7];

Signal controlled junctions, where analytical calculations are set in Technical regulations TP 10/2010 ;

Roundabouts, where analytical calculations are set in Technical regulations TP 10/2010 and in Technical regulations TP 04/2004 [8].

But there is an interesting part in these methodologies, which says that traffic-capacity calculation may be supplemented or even replaced by the virtual simulation of the assumed traffic on the communication network at the solved area or affected junctions. [5] Virtual simulation can be helpful in many traffic research areas such as in public transport priority investigation [9 and 10], traffic light coordination investigation [11], or in finding optimal use of communication network [12 and 13]. Also virtual simulation has an advantage over analytical calculations mainly because of its exceptional features such as clarity, versatility, ability to implement into calculation influence of the surroundings etc. [14].

Here, we can put the question: How much do the simulation outputs correspond (are simulation outputs comparable) to the analytical methods outputs? There is outputs comparison of the analytical traffic-capacity calculation - calculation according to TP

\footnotetext{
* ${ }^{1}$ Lubomir Cernicky, ${ }^{1}$ Alica Kalasova, ${ }^{2}$ Jerzy Mikulski

${ }^{1}$ Department of Road and Urban Transport, Faculty of Operation and Economics of Transport and Communications, University of Zilina, Slovakia ${ }^{2}$ Department of Transport, Faculty of Economics, University of Economics in Katowice, Poland

E-mail: lubomir.cernicky@fpedas.uniza.sk
} 
10/2010 and simulation methods - simulation in Aimsun [15] and simulation in OmniTrans [16] in the following part of the paper.

\section{Investigation procedure}

In order to compare calculation outputs and simulation outputs there were carried out calculations and simulations at the two junctions in the town of Zilina, where traffic load data were available. The junctions and traffic flows are shown in Figs. 1 and 7. The First one was used for the assessment of uncontrolled and signal controlled junctions, the second one for the assessment of roundabouts. The examination procedure was as follows:

1. Delay time calculation according to TP 10/2010 [7];

2. Model creation and simulation in Aimsun [15];

3. Model creation and simulation in OmniTrans [16];

4. All the calculations and simulations were carried out for the traffic flows:

a. according to traffic surveys uniformly reduced by $20 \%$ $(-20 \%)$

b. according to traffic surveys uniformly reduced by $10 \%$ $(-10 \%)$

c. according to traffic surveys (basic state - BS);

d. according to traffic surveys uniformly increased by $10 \%$ $(+10 \%)$;

e. according to traffic surveys uniformly increased by $20 \%$ $(+20 \%)$;

5. Calculations and simulation outputs comparison.

The delay time was chosen as a comparative unit, because the delay time is obtained as an output of calculation according to TP10/2010 and of both simulation software tools.
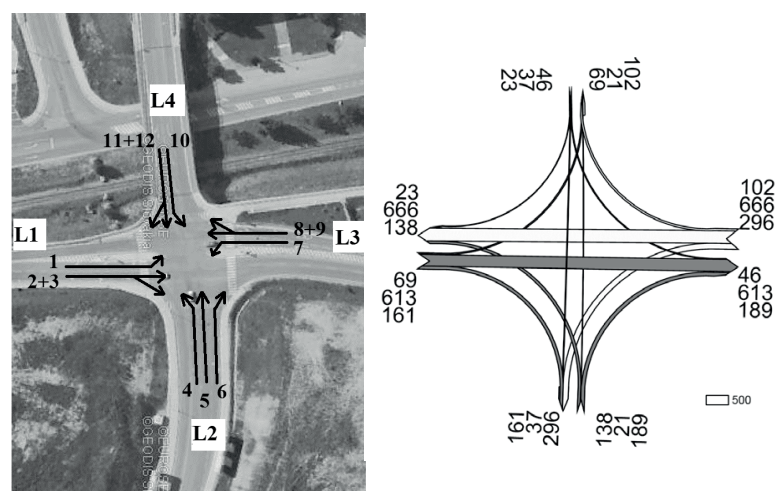

Fig. 1 Junction legs (L1-4) and traffic flows labelling according to TP 10/2010 rules (on left), traffic volume (pcu/h) during traffic peak (on right) [source: authors]

\section{Results}

\section{Uncontrolled junctions}

There are particular traffic flows at the uncontrolled junction, which are not obligated to give way to any other traffic flow, therefore it can be assumed that these traffic flows reach no delay times at uncontrolled junctions and it is not necessary to calculate them during assessment. These flows are represented by traffic flows No. 2, No.8 (straight movement on the main road), No.3, and No. 9 (right turnings from the main road). Other traffic flows are obligated to give way to 1 traffic flow (degree 2), to 2 traffic flows (degree 3 ), or to 3 traffic flows (degree 4).

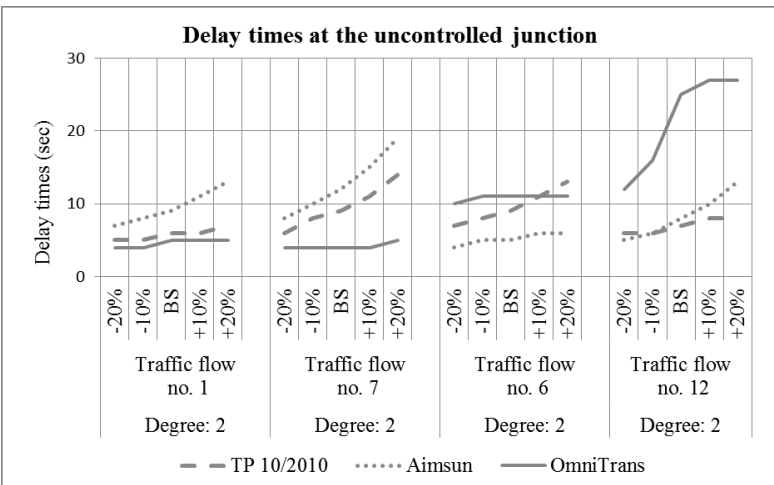

Fig. 2 Simulation and calculation outputs for the uncontrolled junction (traffic flows' degree: 2) [source: authors]

Looking at the traffic flows which are obligated to give way to 1 traffic flow (Fig. 2) it is possible to see slight differences between analytical calculation outputs and simulations outputs, but there are also differences when outputs of 2 simulation tools are compared. The average difference between outputs of TP and Aimsun is about $3.3 \mathrm{sec}$ (maximum of $7 \mathrm{sec}$ ), between TP and OmniTrans about $5.75 \mathrm{~s}$ (maximum of $19 \mathrm{sec}$ ), and between Aimsun and OmniTrans about $8.05 \mathrm{~s}$ (maximum of $17 \mathrm{sec}$ ).

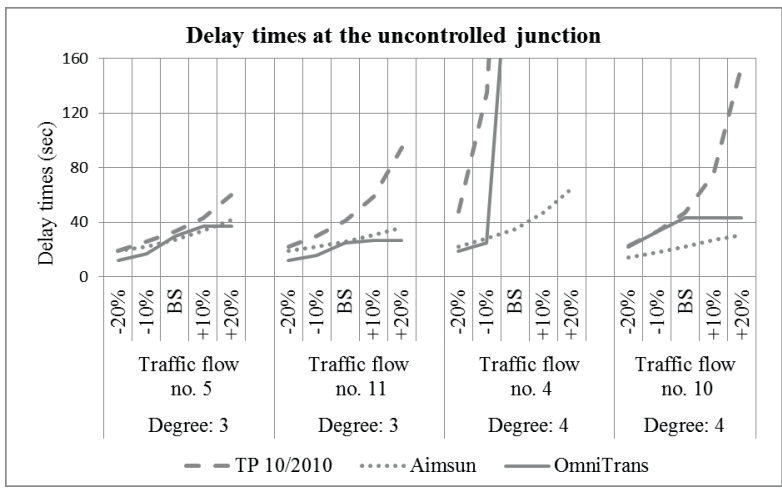

Fig. 3 Simulation and calculation outputs for the uncontrolled junction (traffic flows' degree: 3 and 4) [source: authors]

Looking at the traffic flows that are obligated to give way to 2 traffic flows (Fig. 3, degree: 3, traffic flows No. 5 and No.11) 
it can be seen that increase in delay times according to TP is noticeably higher than increase in delay times according to Aimsun or OmniTrans. The difference in delay times between TP and OmniTrans for the traffic flows increased by $20 \%$ is up to $68 \mathrm{sec}$. But when we take into account the fact that delay times according to Aimsun (OmniTrans) are also higher (40 sec), relative difference between TP and Aimsun is $27.1 \%$, between TP and OmniTrans is $63.3 \%$, and between Aimsun and OmniTrans is equal to $26.7 \%$.

Traffic flows which are obligated to give way to 3 traffic flows (Fig. 3, degree: 4, traffic flow No. 4 and No. 10) are the traffic flows with the highest delay times. Moreover, there are highest differences between calculation and simulation outputs. Calculation outputs according TP show extremely high delay times for the traffic flow No. 4 (up to $2012 \mathrm{sec}$ when the traffic flow is increased by $20 \%$ ). The outputs according to OmniTrans also show high delay times already at the basic traffic volume, but with the maximum value up to $300 \mathrm{sec}$, but the delay time 300 $\mathrm{sec}$ is the maximum delay time that OmniTrans can simulate. Therefore, it is possible to assume that there would be even higher delay times if the traffic flow was higher. In contrast, calculation according to Aimsun showed only slightly increased delay times only up to the value of $65 \mathrm{sec}$. From these findings it is possible to come to the conclusion that at uncontrolled junctions:

- The more the traffic flows to which the assessed traffic flow is obligated to give way, the huger the differences between calculations and simulations outputs are;

- Aimsun gives us the lowest delay times compared to other tools;

\section{Signal controlled junctions}

These calculation and simulation outputs were supplemented with calculation according to Webster method [17] in order to put more objective view into comparison. According to the outputs (see Figs. 2 and 3), there are more significant differences between average delay times of vehicles entering the junction from the main road (Fig. 4), where delay times are lower (around $10 \mathrm{sec}$ ), and vehicles entering from the side roads (Fig. 5), where delay times are around $40 \mathrm{sec}$ and higher. This may be caused mainly by different green, which is much longer for the main road in comparison to side roads ( $56 \mathrm{sec}$ and $69 \mathrm{sec}$ in comparison to 13 $\mathrm{sec}$ and $11 \mathrm{sec}$ ).

Delay time calculation according to Webster gives us the lowest delay time values. Also there are not significant changes in delay time in the case that traffic load decreases/increases by $20 \%$ in any traffic flow. Even traffic flows turning left have not increased delay times values. According to this calculation it would be possible to declare that there are nearly no problems at this junction. The cars can pass through this junction with the acceptable delay also in the case that traffic load during traffic peak will increase by $20 \%$.

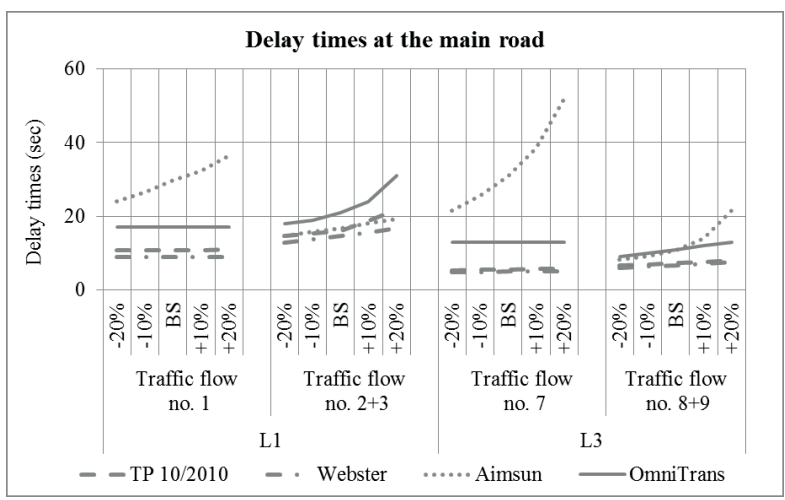

Fig. 4 Simulation and calculation outputs for the signal controlled junction (main road) [source: authors]

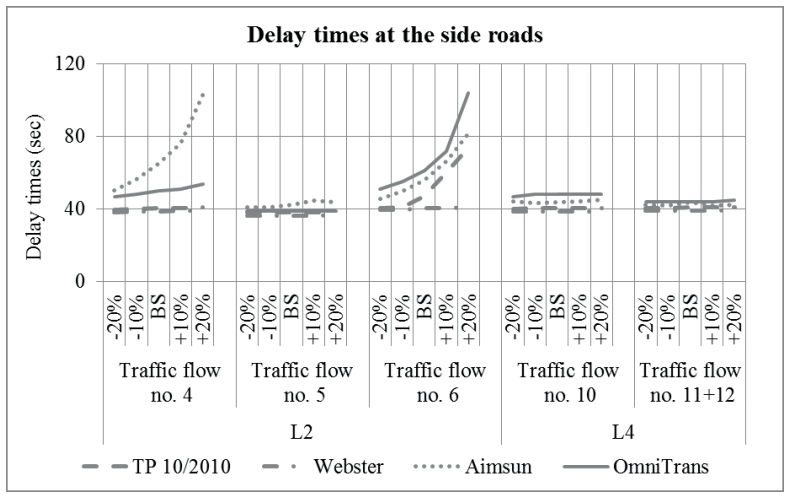

Fig. 5 Simulation and calculation outputs for the signal controlled junction (side roads) [source: authors]

Calculations according to technical regulations TP 10/2010 give us delay time values very similar to Webster's outputs. The total average difference is only about $10 \%$. And also slight decrease/increase in delay time can be seen when traffic load changes and this decrease/increase is very similar to Webster's outputs. The only significant increase compared to Webster can be seen in the delay times of the traffic flow No. 6 (see Fig. 5). According to this calculation it would be possible to point out potential problems at the junction leg L2, where right turning of the traffic flow No. 6 is expected to be problematic. Other traffic flows are expected to have no problems even when the traffic flow increases by $20 \%$.

Simulation in Aimsun can show us significant difference in delay times at particular traffic flows in comparison to Webster and to TP 10/2010. The differences are visible mainly at the left turning traffic flows No. 1, No. 7, and No. 4, but not at the left turning no. 10 (see Figs. 4 and 5). For instance, the traffic flow No. 7 has according to Aimsun the delay time nearly 6 times higher than according to Webster calculations. At the same time, increased delay time is shown at the traffic flow No. 6, which is also problematic according to TP 10/2010. Simulation outputs for other traffic flows are similar to the outputs of other methods. According to Aimsun it would be possible to point out 
problematic left turnings of abovementioned traffic flows (No. 1, No. 7, No. 4) and problematic right turning No. 6.

Simulation in OmniTrans shows slightly higher delay times for nearly all traffic flows in comparison to other methods, but looking at Figs. 4 and 5, the only problematic traffic flow seems to be traffic flow No. 6, where increase in delay time is significant when traffic load is increased. Increased delay times can be also seen at other traffic flows (No. 2+3, and No. 4), but this increase is not very significant.

\section{Roundabouts}
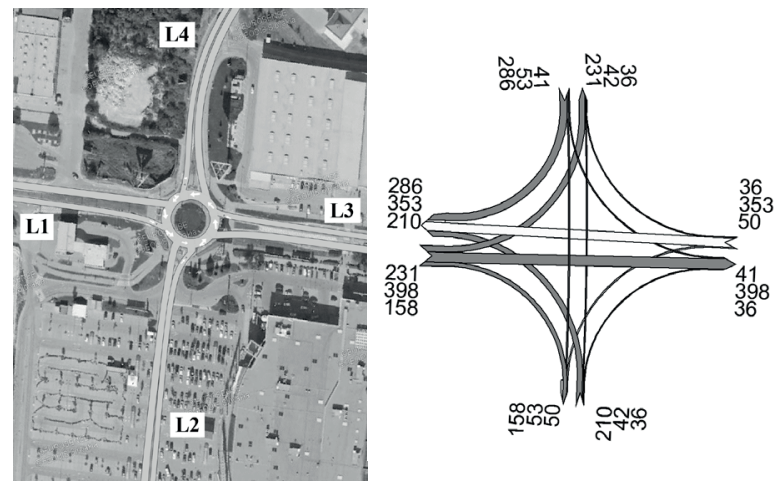

Fig. 6 Assessed roundabout (on left), traffic volume (pcu/h) during traffic peak (on right) [source: authors]

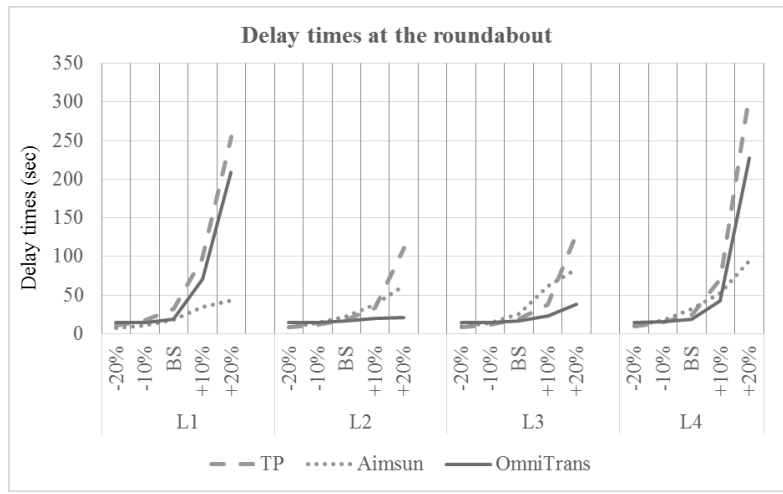

Fig. 7 Simulation and calculation outputs for the roundabout (main road) [source: authors]

Looking at the calculation and simulations outputs for roundabouts (Fig. 6) it can be stated that outputs of all tools are quite comparable when the traffic flow is low. If the traffic flow is decreased by $20 \%$, the output values of all tools show the delay time values between $8 \mathrm{sec}$ and $15 \mathrm{sec}$ and the maximum difference in values between various tools is equal to $6 \mathrm{sec}-$ between TP10/2010 and OmniTrans. But the differences in outputs increase when the traffic flow increases. For the basic state (present traffic volume) the differences in outputs increase to $13 \mathrm{sec}$ (between TP 10/2010 and Aimsun), but for the traffic flow increased by $20 \%$ the differences in outputs increased to 211 sec (between TP10/2010 and Aimsun at the junction legs 1 and 2). You can also see in Fig. 7 that analytical calculation outputs show the highest delay time values at the all junction legs. Aimsun outputs show lower delay times than Omnitrans shows at the junction legs L1 and L4, which are the junction legs where the traffic load is relatively high, and Aimsun shows higher delay times than OmniTrans shows at the junction legs L2 and L4, where the traffic load is relatively low.

\section{Conclusion}

The aim of this paper was to show possibility of using the simulation tools in traffic capacity assessment. These simulation tools were compared to classical analytical calculations and to each other in this paper. Although simulation and analytical calculation were carried out for the same junctions and for the same traffic volumes the outputs of particular tools differed from each other. There were significant differences in outputs at some traffic flows and this might make contrary proposals when two different tools are used at the assessment or might create the space to influence the traffic capacity assessment outputs according to customers' (developers') needs. Therefore, it is possible to recommend further studies that would be focused on verification of particulars methods (e.g. delay times surveys at junctions) and which would clearly confirm the correctness or deviation of outputs from the real situation. Another recommendation is that towns (which will create methodology for traffic-capacity assessment) should pay attention on setting rules for approval/ modification/rejection of the investment plan.

\section{Acknowledgement}

This contribution/publication is the result of the project implementation:

Centre of excellence for systems and services of intelligent transport II.,

ITMS 26220120050 supported by the Research \& Development Operational Programme funded by the ERDF.
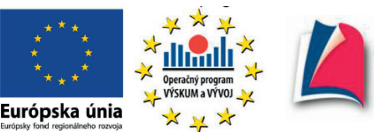

Agentúra Ministerstva školstva, vedy, výskumu a športu SR pre štrukturálne fondy EÚ

"Podporujeme vyskumne aktivity na Slovensku/Projekt je spolufinancovany zo zdrojov EU"

VEGA Project No. 1/0159/13 - KALASOVA, A. and collective: Basic Research of Telematic Systems, Conditions of Their Development and Necessity of Long-term Strategy. University of Zilina, the Faculty of Operation and Economics of Transport and Communications, 2013-2015. 
This paper is prepared with the support of the project "Education quality and human resources development as the pillars of a knowledge society at the Faculty PEDAS, University of Zilina in Zilina.“, ITMS project code 26110230083, University of Zilina.

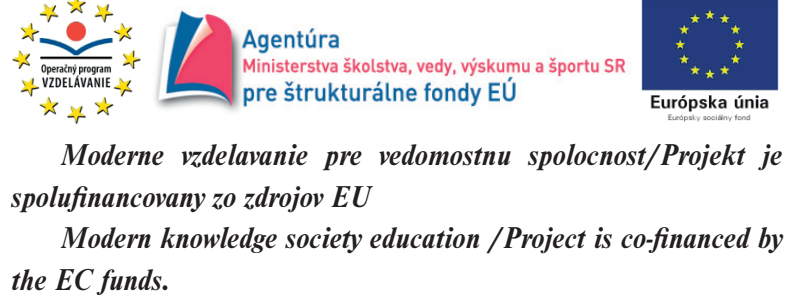
spolufinancovany zo zdrojov $\boldsymbol{E} \boldsymbol{U}$

Modern knowledge society education / Project is co-financed by the EC funds.

\section{References}

[1] GOGOLA, M.: Applications of Methodology of Calculation of the Number of Connections (MCNC), Solving Transport Attendance. Communications - Scientific Letters of the University of Zilina, vol. 7, No. 2, 2005, pp. 17-19.

[2] CSISZAR, C., FOLDES, D.: Analysis and Modelling Methods of Urban Integrated Information System of Transportation. Smart Cities Symposium Prague (SCSP), 2015: IEEE Xplore Digital Library, 2015. pp. 1-10.

[3] KUBASAKOVA, I., KAMPF, R., STOPKA, O.: Logistics Information and Communication Technology. Communications - Scientific Letters of the University of Zilina, vol. 16, No. 2, 2014, pp. 9-13.

[4] DICOVA, J., ONDRUS, J.: Trend of Public Mass Transport Indicators - as a Tool of Transport Management and Development of Regions. Communications - Scientific Letters of the University of Zilina, vol. 12, No. 3A, 2010, pp. 121-126.

[5] Methodology for Traffic-Capacity Assessment of Investment Plans (in Slovak). Bratislava: Official webside. Available at: <http://www. bratislava.sk/VismoOnline_ActionScripts/ File.ashx?id_org=700000\&id_dokumenty=11043591>

[6] STN 73 6102: 2004: Design of Intersection on Highways (in Slovak). Bratislava : SUTN

[7] TP 10/2010: Technical Regulations. Roads Capacity Calculation (in Slovak). Bratislava: Ministry of transport, construction and regional development, 2010. Available online at: 〈http://www.ssc.sk/files/documents/technicke-predpisy/tp2010/tp_10_2010.pdf〉

[8] TP 4/2014: Technical regulations. Roundabouts Designing at Road and Local Communications (in Slovak). Bratislava: Ministry of transport, post and telecommunications, 2014. Available online at: <http://www.ssc.sk/files/documents/technicke-predpisy/ tp2004/tp_04_2004.pdf>

[9] KAlASOVA, A., CERNICKY, L., KUPCUlJAKOVA, J.: The Impact of Public Transport Priority on the Traffic in the Chosen Part of the City of Zilina, Transport Problems: Intern. Scientific J., vol. 9, No. 2, 2014, pp. 19-26.

[10] FOLDES, D., CSISZAR, C.: Route Plan Evaluation Method for Personalised Passenger Information Service. Transport, vol. 30, No. 3, 2015, pp.273-285.

[11] KAlASOVA, A., CERNICKY, L., KUBIKOVA, S.: Microscopic Simulation of Coordinated Route in the City of Zilina. Communications - Scientific Letters of the University of Zilina, vol. 16, No. 2, 2014, pp. 46-50.

[12] KUBIKOVA, S., KALASOVA, A., CERNICKY, L.: Microscopic Simulation of Optimal Use of Communication Network. Communications in Computer and Information Science, vol. 471, 2014, pp. 414-423.

[13] TOMASIKOVA, M., BRUMERCIK, F., NIEOCZYM, A.: Vehicle Simulation Model Criterion, Logi - Scientific J. on Transport and Logistics, vol. 6, No. 1, 2015, pp. 130-135.

[14] BRUMERCIK, F., KRZYWONOS, L.: Integrated Transportation System Simulation. Logi - Scientific J. on Transport and Logistics, vol. 4, No. 2, 2013, pp. 05 - 10

[15] TSS-Transport Simulation Systems - Aimsun. Available online at: 〈http://www.aimsun.com/wp/>

[16] OmniTrans. Available at: 〈http://www.omnitrans.org/>

[17] OHNO, K., MINE, H.: Optimal Traffic Signal Settings - part II. A refinement of Webster's method. Transportation Research, vol. 7, No. 3, 1973, pp. 269-292. 